Pacific Journal of Mathematics

TORSION IN BBSO 


\section{TORSION IN BBSO}

\section{JAMES D. STASHEFF}

The cohomology of BBSO, the classifying space for the stable Grassmanian BSO, is shown to have torsion of order precisely $2^{r}$ for each natural number $r$. Moreover, the elements of order $2^{r}$ appear in a pattern of striking simplicity.

Many of the stable Lie groups and homogeneous spaces have torsion at most of order $2[1,3,5]$. There is one such space, however, with interesting torsion of higher order. This is $B B S O=S U /$ Spin which is of interest in connection with Bott periodicity and in connection with the J-homomorphism [4,7]. By the notation $S U /$ Spin we mean that $B B S O$ can be regarded as the fibre of $B$ Spin $\rightarrow B S U$ or that, up to homotopy, there is a fibration

$$
S U \rightarrow B B S O \rightarrow B \text { Spin }
$$

induced from the universal $S U$ bundle by $B$ Spin $\rightarrow B S U$. The $\bmod$ 2 cohomology $H^{*}\left(B B S O ; Z_{2}\right)$ has been computed by Clough [4]. The purpose of this paper is to compute enough of $H^{*}(B B S O ; Z)$ to obtain the mod 2 Bockstein spectral sequence [2] of $B B S O$.

Given a ring $R$, we shall denote by $R\left[x_{i} \mid i \in I\right]$ the polynomial ring on generators $x_{i}$ indexed by elements of a set $I$. The set $I$ will often be described by an equation or inequality in which case $i$ is to be understood to be a natural number. Similarly $E\left(x_{i} \mid i \in I\right)$ will denote the exterior algebra on generators $x_{i}$. In this case, we will need only $R=Z_{2}$.

Let us recall the results on $B$ Spin as given by Thomas [6] and on $B B S O$ as given by Clough [4].

$$
H^{*}\left(B \text { Spin; } Z_{2}\right) \approx Z_{2}\left[w_{i} \mid i \neq 2^{j}+1\right]
$$

where $w_{i}$ is (the image of) the Stiefel-Whitney class $w_{i}$.

$$
H^{*}(B \operatorname{Spin} ; Z) \approx Z\left[Q_{i} \mid i>0\right] \oplus \hat{T}
$$

where $2 \hat{T}=0$ and $Q_{i} \in H^{4 i}$.

$$
H^{*}\left(B B S O ; Z_{2}\right) \approx E\left(e_{i} \mid i \geqq 3\right)
$$

where $e_{i} \in H^{i}$ and is the image of $w_{i}$ if $i \neq 2^{j}+1$ while $e_{2} j_{+1}$ maps to an indecomposable element in $H^{*}\left(S U ; Z_{2}\right)$.

Now let ${ }_{\beta} E_{r}$ denote the mod 2 Bockstein spectral sequence of $B B S O$ [2]. In particular, ${ }_{\beta} E_{2}=\operatorname{Ker} S q^{1} / \operatorname{Im} S q^{1}$. Now $S q^{1} w_{2 i}=w_{2 i+1}$ in $B S O$ and $S q^{1} w_{2 i+1}=0$ while $S q^{1} e_{2 j}=0$ in $B$ Spin. We will see that 
$e_{2^{j}+1}$ can be chosen to have $S q^{1} e_{2^{j}+1}=0$ except for $S q^{1} e_{3}=e_{4}$. Thus

$$
{ }_{\beta} E_{2}=E\left(e_{3} e_{4}, e_{2^{2+i}}, v_{4 i+1} \mid i>0\right)
$$

where $v_{4 i+1}=e_{2 i} e_{2 i+1}$ except $v_{2^{j+1}}=e_{2^{j+1}} ; j>1$.

\section{THEOREM 1.}

$$
{ }_{\beta} E_{r} \approx E\left(e_{3} e_{4} \cdots e_{2^{r}}, e_{2^{r+i}}, v_{4 i+1} \mid i>0\right)
$$

and $d_{r}\left(e_{3} \cdots e_{2}\right)=e_{2^{r+1}}$ modulo decomposable elements.

To prove Theorem 1, we will exhibit torsion of order $2^{r}$ for all $r$.

Theorem 2. In $H^{*}(B B S O ; Z)$, we have

$$
2^{r} Q_{2^{r}} \neq 0 \text { and } 2^{r+1} Q_{2^{r}}=0 \text {. }
$$

$H^{*}\left(B B S O ; Z_{2}\right)$. We recall some of Clough's observations on $H^{*}\left(B B S O ; Z_{2}\right)$. We know $H^{*}\left(S U ; Z_{2}\right)=E\left(y_{i} \mid i>1\right)$ where $y_{i} \in H^{2 i+1}$ transgresses universally to the mod 2 reduction of the Chern class $c_{i}$ and hence to the image of $w_{i}^{2}$ in $B$ Spin. Thus $w_{i}^{2}=0$ in $B B S O$ for $i \neq 2^{j}+1$ and $y_{2^{j}}$ is the restriction of a class $e_{2^{j+1}+1}$. In particular since $S q^{2^{j}}\left(w_{2^{j-1}+1}\right)^{2}=\left(w_{2^{j}+1}\right)^{2}$ we can take $e_{2^{j}+1}$ to be $S q^{2^{j-1}} S q^{2 j-2} \cdots$ $S q^{4} S q^{2} e_{3}$. The class $e_{3}$ is uniquely determined $\left(H^{3}\left(B B S O ; Z_{2}\right) \approx Z_{2}\right)$ and this definition of $e_{2^{j+1}}$ implies $S q^{1} e_{2^{j+1+1}}=\left(e_{2^{i+1}}\right)^{2}=0$ if $e_{3}^{2}=0$. The only alternative to $e_{3}^{2}=0$ is $e_{3}^{2}=e_{6}$; there is no other class in this dimension. Since $S q^{1} w_{6}=w_{7}$ in $B$ Spin and $w_{6}, w_{7}$ map to $e_{6}, e_{7}$, we have $S q^{1} e_{6}=e_{7}$ but $S q^{1}\left(e_{3}\right)^{2}=0$; therefore $e_{3}^{2}$ must be zero.

$H^{*}(B B S O, Z)$. Consider $B B S O$ as the fibre of $B$ Spin $\rightarrow B S U$. The latter map factors: $B$ Spin $\stackrel{\pi}{\longrightarrow} B S O \rightarrow B S U$. Recall that

$$
H^{*}(B S U ; Z)=Z\left[c_{i} \mid i>1\right] \text { and } H^{*}(B S O ; Z)=Z\left[P_{i}\right] \oplus T
$$

where $T$ is the torsion ideal, $2 T=0, c_{2 i+1}$ maps into $T$ and $c_{2 i}$ maps to $P_{i}$. To determine $\operatorname{Im}\left(H^{*}(B\right.$ Spin $\left.)\right)$ in $H^{*}(B B S O)$, we need to know $\pi^{*}\left[P_{i}\right]$ in $H^{*}(B$ Spin $)$.

Theorem 3 (Thomas [6]). If $i$ is not a power of $2, \pi^{*} P_{i}=Q_{i}$. If $j=2^{r}, r>0, \pi^{*} P_{2 j}=2 Q_{2 j}+Q_{j}^{2}-\pi^{*} \Phi_{2 j} . \pi^{*} P_{1}=2 Q_{1}$.

Lemma. $\pi^{*} \Phi_{2 j}$ maps into $\operatorname{Im} T \subset H^{*}(B B S O)$.

Proof. $H^{*}(B S O ; Z)$ maps onto $\operatorname{Im} T$ in $H^{*}(B B S O)$ since $H^{*}(B S U)$ maps onto the $Z\left[P_{i}\right]$ part.

Since $\pi^{*} P_{j}$ goes to zero in $B B S O$, we have in $H^{*}(B B S O ; Z)$ 


$$
\begin{aligned}
& 2 Q_{2 j}=-Q_{j}^{2}+t \quad \text { where } 2 t=0 \text { and } j=2^{r} . \\
& 2 Q_{1}=0 .
\end{aligned}
$$

By iteration we find

$$
2^{r+1} Q_{2^{r}}= \pm 2 Q_{2^{r}} Q_{2^{r-1}} \cdots Q_{2}\left(Q_{1}\right)^{2}=0 .
$$

To determine the order of $Q_{2^{i}}$ in $B B S O$, consider $\Gamma(u \mid 2 u=0)$, a divided polynomial algebra on a single generator $u$ of dimension 4 and order 2 ; i.e., additively $\Gamma$ has generators $\gamma_{i}(u)$ in dimension $4 i$ and the multiplication table is $\gamma_{i}(u) \gamma_{j}(u)=(i, j) \gamma_{i+j}(u)$ where $(i, j)$ is the binomial coefficient $\{(i+j) ! / i ! j !\}$.

In particular $i ! \gamma_{i}(u)=u^{i}$.

We construct a map $f$ from $\operatorname{Im}\left(H^{*}(B\right.$ Spin; $\left.Z) \rightarrow H^{*}(B B S O ; Z)\right)$ to $\Gamma$ by mapping $\hat{T}$ to zero, $Q_{i}$ to zero for $i \neq 2^{j}$ and $Q_{2^{j}}$ to $-\gamma_{2}\left(f\left(Q_{2 j-1}\right)\right)$ with $f\left(Q_{1}\right)=u$. Since $2 Q_{2 j}=-Q_{2^{j-1}}^{2}+\pi^{*} \Phi_{2 j}$, and $\Phi_{2^{j}}$ goes into Im $\hat{T}$ in $B B S O$, the map $f$ is well defined. Since for any $x$, the order of $\gamma_{2}(x)$ is twice the order of $x$, we have

$$
\text { ord } f\left(Q_{2^{\jmath}}\right)=2 \operatorname{ord} f\left(Q_{2^{j-1}}\right)=2^{j} \text { ord } f\left(Q_{1}\right)=2^{j+1} \text {. }
$$

Thus the order of $Q_{2^{j}}$ is at least $2^{j+1}$ and that $2^{j+1} Q_{2^{i}}$ is in fact zero we have already seen.

Thus we have $2^{r}$ torsion for each $r$. From the exact cohomology sequence derived from $0 \rightarrow Z \stackrel{2^{r}}{\longrightarrow} Z \rightarrow Z_{2^{r}} \rightarrow 0$, we see that $Q_{2^{r-1}}=$ $\beta_{2^{r}}^{\infty} x_{r}$ for some class $x_{r} \in H^{*}\left(B B S O ; Z_{2^{r}}\right)$, where $\beta_{2^{r}}^{\infty}$ is the connecting homomorphism $H^{*}\left(; Z_{2 r}\right) \rightarrow H^{*+1}(; Z)$.

Lemma. $\quad\left(\beta_{2^{r}}^{\infty} x_{r}\right)_{2}=d_{r}\left(x_{r}\right)_{2}$ where ()$_{2}$ means reduction mod 2.

Proof. Recall how $d_{r}$ is defined: $d_{r}(x)=\left(\beta_{2}^{\infty}(x) / 2^{r-1}\right)_{2}$. From the commutativity of the diagram

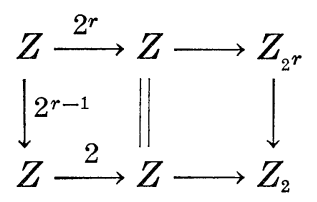

it follows that $\beta_{2}^{\infty}=2^{r-1} \beta_{2^{r}}^{\infty}$. In particular, $d_{r}\left(x_{r}\right)_{2}=\left(Q_{2^{r-1}}\right)_{2}$. According to Thomas, $\left(Q_{2^{r-1}}\right)_{2}=\pi^{*}\left(w_{2^{r+1}}+\psi_{2^{r+1}}\right)$ where $\psi_{2^{r+1}}$ is decomposable. In particular, $\left(Q_{1}\right)_{2}=W_{4}$.

We prove Theorem 2 by induction. Since

$$
S q^{1} w_{2 i}=w_{2 i+1} \text { and } S q^{1} w_{2 i+1}=0,
$$

we know $S q^{1} e_{2 i}=e_{2 i+1}$ and $S q^{1} e_{2 i+1}=0$ unless $i=2^{j}$. Since we have chosen $e_{2^{j+1}}=S q^{2 j-1} \cdots S q^{2} e_{3}$, we have $S q^{1} e_{2^{j+1}}=\left(e_{2 j-1+1}\right)^{2}=0$ for 
$j \geqq 2$. For $j=1$, we have $S q^{1} e_{3}=e_{4}$ because $e_{4}=\left(Q_{1}\right)_{2}$ which is in the image of $S q^{1}$ since $2 Q_{1}=0$.

Thus

$$
\begin{aligned}
{ }_{\beta} E_{2} & =\operatorname{Ker} S q^{1} / \operatorname{Im} S q^{1} \\
& =E\left(e_{3} e_{4}\right) \otimes E\left(e_{2 i} e_{2 i+1} \mid 2<i \neq 2^{j}\right) \otimes E\left(e_{2 j+1}, e_{2 j_{+1}} \mid j \geqq 2\right) .
\end{aligned}
$$

Since $d_{2}\left(x_{2}\right)_{2}=\left(Q_{2}\right)_{2}=e_{8}$, we must have $x_{2}=e_{3} e_{4}$.

In general $d_{r}\left(x_{r}\right)_{2}=\left(Q_{2^{r-1}}\right)_{2}=e_{2^{r+1}}$ modulo decomposables. Now consider $H^{*}(B B S O ; Q)$. Since $H^{*}(B S O ; Q)=Q\left[P_{i}\right]$ with the usual diagonal $m^{*}\left(P_{i}\right)=\sum_{j+h=i} P_{j} \otimes P_{k}$, we have $H^{*}(B B S O ; Q)=E\left(R_{i}\right)$ where $\operatorname{dim} R_{i} \in H^{4 j+1}$. Thus ${ }_{\beta} E_{\infty}=E\left(S_{4 i+1}\right)$ and the only possibility is

$$
\begin{aligned}
& S_{4 i+1}=e_{2 i} e_{2 i+1} i \neq 2^{j}, \\
& S_{2^{i+1}}=e_{2^{i+1}}
\end{aligned}
$$

modulo terms decomposable in terms of the $S_{4 i+1}$. This leaves $e_{3} e_{4} \ldots$ $e_{2^{r}}$ as the only possibility for $x_{r}$, i.e., $d_{r}\left(e_{3} e_{4} \cdots e_{2^{r}}\right)=e_{2^{r+1}} \bmod$ decomposables as claimed.

\section{BIBLIOGRAPHY}

1. A. Borel, La cohomologie mod 2 des certains espaces homogènes, Comm. Math. Helv. 27 (1953), 165-197.

2. W. Browder, Torsion in H-spaces, Ann. of Math. 74 (1961), 24-51.

3. H. Cartan, Séminaire-1959/60, Exposés 3, 17, Paris, 1961.

4. R. R. Clough, Calculation of $H *\left(B_{\operatorname{Im}(J)} ; Z_{2}\right)$ (to appear).

5. E. Dyer and R. K. Lashof, A topological proof of the Bott periodicity theorem, Ann. Mat. Pura Appl. (4) 54 (1961), 231-254.

6. E. Thomas, On the cohomology groups of the classifying space for the stable spinor group, Bol. Soc. Mat. Mex. (1962), 57-69.

7. G. W. Whitehead, On the homotopy groups of spheres and rotation groups, Ann. of Math. 43 (1942), 634-640.

Received May 3, 1968. Research supported in part by NSF Grant GP-6101. The author is an Alfred P. Sloan Fellow. 


\section{PACIFIC JOURNAL OF MATHEMATICS}

\section{EDITORS}

\author{
H. ROYDEN \\ Stanford University \\ Stanford, California \\ R. R Phelps \\ University of Washington \\ Seattle, Washington 98105
}

\author{
J. Dugundui \\ Department of Mathematics \\ University of Southern California \\ Los Angeles, California 90007
}

RICHARD ARENS

University of California

Los Angeles, California 90024

\section{ASSOCIATE EDITORS}
E. F. BeCKENBACH
B. H. NeUmanN
F. WolF
K. YosidA

\section{SUPPORTING INSTITUTIONS}

\author{
UNIVERSITY OF BRITISH COLUMBIA \\ CALIFORNIA INSTITUTE OF TECHNOLOGY \\ UNIVERSITY OF CALIFORNIA \\ MONTANA STATE UNIVERSITY \\ UNIVERSITY OF NEVADA \\ NEW MEXICO STATE UNIVERSITY \\ OREGON STATE UNIVERSITY \\ UNIVERSITY OF OREGON \\ OSAKA UNIVERSITY \\ UNIVERSITY OF SOUTHERN CALIFORNIA
}

\author{
STANFORD UNIVERSITY \\ UNIVERSITY OF TOKYO \\ UNIVERSITY OF UTAH \\ WASHINGTON STATE UNIVERSITY \\ UNIVERSITY OF WASHINGTON

$* * * * *$
AMERICAN MATHEMATICAL SOCIETY
CHEVRON RESEARCH CORPORATION
TRW SYSTEMS
NAVAL WEAPONS CENTER

The Supporting Institutions listed above contribute to the cost of publication of this Journal, but they are not owners or publishers and have no responsibility for its content or policies.

Mathematical papers intended for publication in the Pacific Journal of Mathematics should be in typed form or offset-reproduced, double spaced with large margins. Underline Greek letters in red, German in green, and script in blue. The first paragraph or two must be capable of being used separately as a synopsis of the entire paper. It should not contain references to the bibliography. Manuscripts, in duplicate if possible, may be sent to any one of the four editors. Please classify according to the scheme of Math. Rev. 36, 1539-1546. All other communications to the editors should be addressed to the managing editor, Richard Arens, University of California, Los Angeles, California, 90024.

50 reprints are provided free for each article; additional copies may be obtained at cost in multiples of 50 .

The Pacific Journal of Mathematics is published monthly. Effective with Volume 16 the price per volume (3 numbers) is $\$ 8.00$; single issues, $\$ 3.00$. Special price for current issues to individual faculty members of supporting institutions and to individual members of the American Mathematical Society: $\$ 4.00$ per volume; single issues $\$ 1.50$. Back numbers are available.

Subscriptions, orders for back numbers, and changes of address should be sent to Pacific Journal of Mathematics, 103 Highland Boulevard, Berkeley, California, 94708.

PUBLISHED BY PACIFIC JOURNAL OF MATHEMATICS, A NON-PROFIT CORPORATION

Printed at Kokusai Bunken Insatsusha (International Academic Printing Co., Ltd.), 7-17. Fujimi 2-chome, Chiyoda-ku, Tokyo, Japan. 


\section{Pacific Journal of Mathematics}

Vol. 28, No. 3

May, 1969

Jon F. Carlson, Automorphisms of groups of similitudes over $F_{3} \ldots \ldots \ldots$

W. Wistar (William) Comfort, Neil Hindman and Stelios A. Negrepontis,

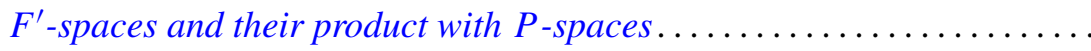

Archie Gail Gibson, Triples of operator-valued functions related to the unit

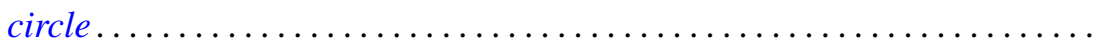

David Saul Gillman, Free curves in $E^{3}$

E. A. Heard and James Howard Wells, An interpolation problem for

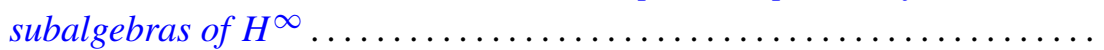

Albert Emerson Hurd, A uniqueness theorem for weak solutions of symmetric

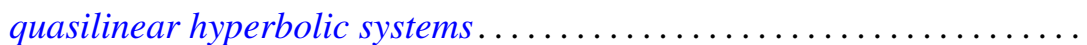

E. W. Johnson and J. P. Lediaev, Representable distributive Noether

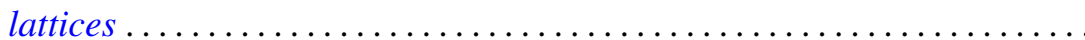

David G. Kendall, Incidence matrices, interval graphs and seriation in

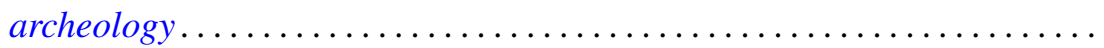
565

Robert Leroy Kruse, On the join of subnormal elements in a lattice ....... 571

D. B. Lahiri, Some restricted partition functions; Congruences modulo 3 .... 575

Norman D. Lane and Kamla Devi Singh, Strong cyclic, parabolic and conical differentiability........................................

William Franklin Lucas, Games with unique solutions that are

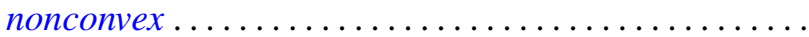

Eugene A. Maier, Representation of real numbers by generalized geometric series.

Daniel Paul Maki, A note on recursively defined orthogonal polynomials ...

Mark Mandelker, $F^{\prime}$-spaces and z-embedded subspaces ...

James R. McLaughlin and Justin Jesse Price, Comparison of Haar series with gaps with trigonometric series

Ernest A. Michael and A. H. Stone, Quotients of the space of irrationals ....

William H. Mills and Neal Zierler, On a conjecture of Golomb ...

J. N. Pandey, An extension of Haimo's form of Hankel convolutions ...

Terence John Reed, On the boundary correspondence of quasiconformal mappings of domains bounded by quasicircles...

Haskell Paul Rosenthal, A characterization of the linear sets satisfying Herz's criterion.

George Thomas Sallee, The maximal set of constant width in a lattice...

I. H. Sheth, On normaloid operators

James D. Stasheff, Torsion in BBSO ...

Billy Joe Thorne, A - P congruences on Baer semigroups.

Robert Breckenridge Warfield, Jr., Purity and algebraic compactness for

modules... 